\title{
Wear Characteristics of the Material Specimen and Method of Predicting Wear in Floating Spline Couplings of Aero-Engine
}

\author{
Xiangzhen Xue, ${ }^{1}$ Sanmin Wang, ${ }^{1}$ Jie $Y u^{2}$ and Liyun ${ }^{2}{ }^{2}$ \\ ${ }^{1}$ School of Mechanical Engineering, Northwestern Polytechnical University, Xi'an 710072, China \\ ${ }^{2} 35$ th Department, Xi'an Space Engine Factory, Xi'an 710061, China \\ Correspondence should be addressed to Xiangzhen Xue; a_zheny@163.com
}

Received 24 May 2017; Revised 3 October 2017; Accepted 4 October 2017; Published 14 December 2017

Academic Editor: Nicolas Avdelidis

Copyright ( 2017 Xiangzhen Xue et al. This is an open access article distributed under the Creative Commons Attribution License, which permits unrestricted use, distribution, and reproduction in any medium, provided the original work is properly cited.

\begin{abstract}
In order to reduce wear and design high-performance spline coupling, the friction coefficient, wear coefficient, and wear depth of 14 groups of material specimens were tested using multifunctional friction and wear tester. The effect of materials, loads, rotation speed, and surface treatment on friction coefficient, wear coefficient, and wear depth was investigated. A method using an Archard's equation based on the finite element method to calculate the wear depth of 14 groups of material specimens was proposed, and the results were consistent with the experimental results. Then, the wear of a floating involute spline coupling of aero-engine was predicted using this method. It can be concluded that carburizing and silvering can decrease the friction coefficient. The wear and wear coefficient decreased after carburizing. So, it is necessary to take $18 \mathrm{CrNi} 4 \mathrm{~A}$ with carburization and $32 \mathrm{Cr} 3 \mathrm{MoVA}$ with nitridation as the material of the spline coupling in aero-engine to minimize wear. Furthermore, the method presented to predicate the wear of spline coupling in this work provided a good fundament for the fatigue prediction methodology of spline coupling.
\end{abstract}

\section{Introduction}

Two kinds of involute splines are widely used in aeromechanical transmission systems including aero-reducer and aerospace engine turbine pump [1-4], and they are fixed spline and floating spline. For the first one, internal spline and external spline are relatively static. The failure of it was mainly caused by fretting wear due to the special load forms of variable torque, bending moment, and axial force during the taking-off, cruising, and landing processes of an aircraft [5-7]. So, these days, there have lots of relation studies on it. Madge et al. have studied the contactevolution of spline couplings and analyzed the role of fretting wear on the fretting fatigue $[8,9]$. Ding et al proposed a finite element method to predict the fretting wear of spline couplings [10]. Houghton et al. presented an experimental method to simulate the multiaxial fretting conditions between spline teeth, basing on the concept of a simplified representative test [11]. Ratsimba et al. have investigated the friction and wear properties of spline couplings using a cylinder-on-flat fretting testing [12].
Moreover, McColl et al. also established a finite element model based on a modified Archard's equation for simulating both the wear and the evolution of fretting variables with number of wear cycles in a cylinder-on-flat fretting configuration [13]. Cuffaro et al. investigated the behavior of spline couplings in real working conditions and fretting wear phenomena particularly using a novel spline coupling test rig. Simultaneously, an estimation of the Ruiz parameter has been obtained [14, 15].

For the second one, mechanical sliding along axial direction is generated between the internal and external splines. Thus, the failure caused by mechanical (abrasive) wear is serious. But it can be gotten that there was almost no literature about the predicting wear of aero-engine floating spline coupling from the literature above.

According to the latest statistics, in the failure of the helicopter transmission system, the failure caused by these spline couplings accounts for about $10 \% \sim 20 \%$, and the failure caused by wear accounts for more than $90 \%$. It affects the stability and safety of aero-engine transmission systems seriously. Therefore, it has a great demand of 
TABLE 1: Chemical composition of alloy steels $18 \mathrm{CrNi} 4 \mathrm{~A}$ and $32 \mathrm{Cr} 3 \mathrm{MoVA}$.

\begin{tabular}{|c|c|c|c|c|c|c|c|c|c|c|c|c|}
\hline Composition/wt $\%$ & $\mathrm{C}$ & $\mathrm{Mn}$ & $\mathrm{Si}$ & $\mathrm{Ni}$ & $\mathrm{Cr}$ & $S$ & $\mathrm{P}$ & $\mathrm{Al}$ & $\mathrm{V}$ & Mo & $\mathrm{Cu}$ & $\mathrm{Fe}$ \\
\hline $18 \mathrm{CrNi} 4 \mathrm{~A}$ & 0.17 & 0.47 & 0.15 & 3.93 & 0.90 & 0.005 & 0.009 & 0.055 & - & - & - & 94.311 \\
\hline $32 \mathrm{Cr} 3 \mathrm{MoVA}$ & 0.34 & 0.60 & 0.38 & 0.06 & 3.07 & 0.002 & - & - & 0.26 & 0.99 & 0.07 & 94.228 \\
\hline
\end{tabular}

TABLE 2: Mechanical properties of alloy steels $18 \mathrm{CrNi} 4 \mathrm{~A}$ and $32 \mathrm{Cr} 3 \mathrm{MoVA}$.

\begin{tabular}{lcr}
\hline & $18 \mathrm{CrNi} 4 \mathrm{~A}$ & $32 \mathrm{Cr} 3 \mathrm{MoVA}$ \\
\hline $\mathrm{E} / \mathrm{GPa}$ & 205.1 & 211 \\
$\mathrm{G} / \mathrm{GPa}$ & 79.9 & 82.4 \\
$\sigma_{0.2} / \mathrm{MPa}$ & $\geq 980$ & $\geq 880$ \\
$\sigma_{\mathrm{b}} / \mathrm{MPa}$ & $1176-1274$ & $1080-1280$ \\
\hline
\end{tabular}

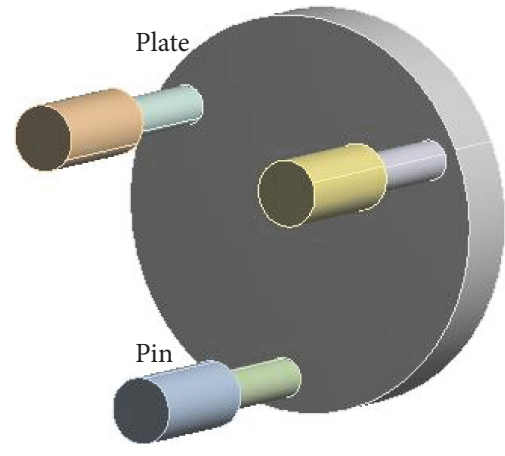

(a)

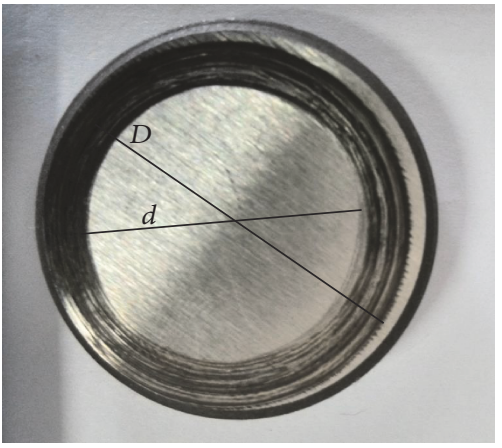

(b)

FIGURE 1: Experimental specimen configuration and worn trace: (a) scheme of pin-on-plate couple; (b) worn trace formed on plate specimen.

engineering background to investigate on the wear of floating spline coupling. Guo et al. investigated the gearcoupling contact and loads under considering the effects of the misalignment, torque, and friction [16]. Similarly, Leen et al. have studied the frictional contact in spline couplings $[17,18]$ and investigated the effect of axial profile modification on friction coefficient with considering the coupling which is under combined torque and axial loads [19]. Hu et al. analyzed the influences of the contact length, friction coefficient, spline wall thickness on the contact stress, and slip distribution of aviation involute spline couplings using a finite element method [20]. Though these studies provide some effective measures to decrease the wear damage by improving the loads and structure geometries, the failure of wear is mainly resulted from many factors: load condition, material pair, heat treatment, lubricating situation, geometric parameters, and surface temperature. So, a lot of efforts have been performed to decrease the wear damage of involute spline couplings by controlling other factors.

In order to improve the wear resistance and reliability of spline coupling, the influences of surface treatment, loads, and rotation on the friction and wear properties of the materials used in spline coupling were investigated experimentally in this work. A method was proposed to predict accurately the wear of floating spline coupling basing on an Archard's equation and finite element method.

\section{Friction Experimental}

2.1. Experimental Specimen. In the past, lots of carburizing steels were usually used to manufacture the aviation parts, such as $12 \mathrm{CrNi} 3 \mathrm{~A}, 14 \mathrm{CrMnSiNi} 2 \mathrm{MoA}, 18 \mathrm{Cr} 2 \mathrm{Ni} 4 \mathrm{WA}$, and $20 \mathrm{CrNi} 3 \mathrm{~A}$. Later, more and more materials are introduced; for example, the carburizing steels are $16 \mathrm{Cr} 3 \mathrm{NiWMoVNbE}$, $16 \mathrm{CrNi} 4 \mathrm{MoA}$, and $18 \mathrm{CrNi} 4 \mathrm{~A}$. The nitridation steels are $30 \mathrm{Cr} 3 \mathrm{MoA}, 32 \mathrm{Cr} 3 \mathrm{MoVA}, 38 \mathrm{CrMoAlA}$, and so on. Alloy steels $18 \mathrm{CrNi} 4 \mathrm{~A}$ and $32 \mathrm{Cr} 3 \mathrm{MoVA}$ were chosen as the investigated materials since they were widely used to manufacture spline coupling. The chemical compositions and mechanical properties of these two materials were listed in Tables 1 and 2 , respectively. $18 \mathrm{CrNi} 4 \mathrm{~A}$ was one kind of nickel chromium alloy structural steel possessing good comprehensive performance. Alloy steel 32Cr3MoVA had high hardness, good comprehensive performance, and thermal stability.

The friction and wear properties of these materials were tested under a universal friction tester with a pin-on-flat configuration as shown in Figure 1. The material of pin specimen was alloy steel $18 \mathrm{CrNi}$ A. The big end of pin specimen was clamped by the friction tester, whose diameter was $5 \mathrm{~mm}$. Another end with the diameter of $3 \mathrm{~mm}$ was used to grind with the plate specimen. The length of these two parts was $10 \mathrm{~mm}$. The dimension of plate specimen was $\Phi$ $30 \mathrm{~mm} \times 5 \mathrm{~mm}$, which was made of alloy steels $18 \mathrm{CrNi} 4 \mathrm{~A}$ or $32 \mathrm{Cr} 3 \mathrm{MoVA}$. 
Furthermore, the pin and plate specimens were treated via carburization or nitridation processes for investigating the effect of surface treatment on the friction and wear properties. The thickness of carburization and nitridation layers was $0.5-0.7 \mathrm{~mm}$ and $0.4-0.6 \mathrm{~mm}$, respectively. Moreover, some specimens were silvered on the carburization or nitridation layers.

2.2. Experimental Procedure. Prior to the friction testing, the specimens were cleaned by an ultrasonic cleaning machine. The mass of the specimens was measured by a microbalance with the accuracy of $0.1 \mathrm{mg}$. During the testing, three same pins were arranged on one plate to form friction couples and then immersed into the lubricating oil to simulate the working environment of spline coupling. These friction couples were fixed on the friction and wear tester, the lever was levelled, and the load was applied. The testing time was set as $120 \mathrm{~min}$, and the friction force was measured by a strain gauge. The room temperature and relative humidity were $20^{\circ} \mathrm{C}$ and $50 \mathrm{RH}$, respectively. Table 3 exhibits the experimental materials and testing conditions.

After every 20 minutes, the testing was interrupted to measure the mass loss with the microbalance of cleaned specimens and the length of $D$ and $d$ by a micrometer with the accuracy of $0.01 \mathrm{~mm}$. Then, the friction coefficient of the materials was calculated by. The wear resistance was described by wear coefficient $(k)$ presented as [7]. The wear depth $(h)$ of plate specimen was calculated according to. Before and after the whole testing, the worn surface of plate specimen was observed by an optical microscope.

$$
\begin{aligned}
& \mu=\frac{F_{f}}{F_{N}}, \\
& k=\frac{m_{w}}{\left(\rho \cdot \delta \cdot F_{N}\right)}, \\
& \delta=n_{n} \cdot t \cdot l_{z}, \\
& l_{z}=\frac{\pi \cdot(D+d)}{2}, \\
& h=\frac{m_{w}}{\left(\rho \cdot s_{w}\right)}, \\
& s_{w}=\frac{\pi \cdot\left(D^{2}-d^{2}\right)}{4},
\end{aligned}
$$

where $F_{f}$ and $F_{N}$ are the maximum friction force and applied normal load $(\mathrm{N}), m_{w}$ is the mass loss of specimen $(\mathrm{g}), \rho$ is the density of the materials $\left(\mathrm{g} / \mathrm{cm}^{3}\right), \delta$ is the sliding distance ( $\mathrm{mm}), n_{n}$ is the rotation speed of pins ( $\left.\mathrm{r} / \mathrm{min}\right), t$ is the testing time $(120 \mathrm{~min}), l_{z}$ is the perimeter of worn trace formed on plate specimen $(\mathrm{mm}), D$ and $d$ denote the outer and inner diameters of worn trace shown in Figure 1(b) $(\mathrm{mm}), s_{w}$ is the apparent area of worn trace $\left(\mathrm{mm}^{2}\right)$.

\subsection{Results and Discussion}

2.3.1. Friction Coefficient. Tables 4, 5, and 6 show the results of the experiment, and Figure 2(a) shows the result of friction coefficients for different pairs of materials. As can be seen from Table 3, materials of the 2 nd group and the 5th group are different, and materials of the 3rd group and the 6th group are different. Figure 2(a) shows that the plate made of $18 \mathrm{CrNi} 4 \mathrm{~A}$ (number 1 and 2 couples) has bigger fluctuating range than that of $32 \mathrm{Cr} 3 \mathrm{MoVA}$ (number 3 and 4 couples). The friction coefficient of number 2 decreases with the increasing time, which has a higher average value of 0.149 . Testing couple number 4 has low and steady friction coefficient, whose average friction coefficient is about 0.115 (Figure 2(a)). It always can be seen that the friction coefficient of couple numbers 3 and 4 increases with the increasing time, whereas the friction coefficient of couple numbers 1 and 2 decreases at last. It is attributed to the different hardness of $18 \mathrm{CrNi} 4 \mathrm{~A}$ and $32 \mathrm{Cr} 3 \mathrm{MoVA}$.

Figure 2(b) shows the result of friction coefficients for different surface treatment. As can be seen from Table 3, the surface treatments of the 5th group and the 7th group are different, and the surface treatments of the 6th group and the 8th group are different. From Figure 2(b), compared with the nontreated case (Figure 2(a)), the average friction coefficient is increased by the carburation or nitridation treatments of plate specimen. For example, the average friction coefficient is increased from 0.107 to 0.121 and from 0.120 to 0.127 for the plate made of carburized $18 \mathrm{CrNi} 4 \mathrm{~A}$ and nitrided $32 \mathrm{Cr} 3 \mathrm{MoVA}$, respectively. These results indicate that the friction coefficient of nontreated materials is larger than that of the carburized one. When the carburation or nitridation layers are silvered, the average friction coefficients present a decrease whereas the variations of friction coefficient with time are enhanced. Testing couple number 6 has a relatively low friction coefficient of 0.066 . It means that silvering onto the carburization or nitridation layers can further decrease the friction coefficient.

Furthermore, the applied load and rotation speed have an important influence on the friction coefficient (Figures 2(c) and $2(\mathrm{~d})$ ). The friction coefficient decreases with the increasing load from 50 to $150 \mathrm{~N}$. It is because that the friction properties of metal material are related to the deformation and interaction of friction surfaces. Under the lower normal load of $50 \mathrm{~N}$, the interfacial shear stress on the friction surfaces is insufficient to deform the micro peaks and wear debris. The friction process is dominated by the interaction of uneven friction surfaces, leading to a higher friction coefficient. As the normal load increases, the deformation of micro peaks and compaction of wear debris are enhanced by the increased interfacial shear stress, which favors the formation of smooth surfaces thereby decreases the friction coefficient. It exhibits an increasing trend as the rotation speed increases from 150 to $260 \mathrm{r} / \mathrm{min}$, whereas it decreases as the rotation speed increases to $360 \mathrm{r} / \mathrm{min}$. It is because that there are boundary friction and fluid friction when the speed is slow. And as the speed increases, the dynamic pressure oil film is formed, and the friction coefficient decreases. 
TABLE 3: Materials and testing conditions.

\begin{tabular}{|c|c|c|c|c|c|c|}
\hline \multirow{2}{*}{ Testing couple } & \multicolumn{2}{|c|}{ Pin (3) } & \multicolumn{2}{|c|}{ Plate (1) } & \multirow{2}{*}{ Load/N } & \multirow{2}{*}{ Speed $/ \mathrm{r} \cdot \mathrm{min}^{-1}$} \\
\hline & Material & Treatment & Material & Treatment & & \\
\hline 1 & $18 \mathrm{CrNi} 4 \mathrm{~A}$ & Carburization & $18 \mathrm{CrNi} 4 \mathrm{~A}$ & Nontreatment & 100 & 200 \\
\hline 2 & $18 \mathrm{CrNi} 4 \mathrm{~A}$ & Nontreatment & $18 \mathrm{CrNi} 4 \mathrm{~A}$ & Nontreatment & 100 & 200 \\
\hline 3 & $18 \mathrm{CrNi} 4 \mathrm{~A}$ & Carburization & $32 \mathrm{Cr} 3 \mathrm{MoVA}$ & Nontreatment & 100 & 200 \\
\hline 4 & $18 \mathrm{CrNi} 4 \mathrm{~A}$ & Nontreatment & $32 \mathrm{Cr} 3 \mathrm{MoVA}$ & Nontreatment & 100 & 200 \\
\hline 5 & $18 \mathrm{CrNi} 4 \mathrm{~A}$ & Carburization & $18 \mathrm{CrNi} 4 \mathrm{~A}$ & Carburization & 100 & 200 \\
\hline 6 & $18 \mathrm{CrNi} 4 \mathrm{~A}$ & Carburization* & $18 \mathrm{CrNi} 4 \mathrm{~A}$ & Carburization* & 100 & 200 \\
\hline 7 & $18 \mathrm{CrNi} 4 \mathrm{~A}$ & Carburization & $32 \mathrm{Cr} 3 \mathrm{MoVA}$ & Nitridation & 100 & 200 \\
\hline 8 & $18 \mathrm{CrNi} 4 \mathrm{~A}$ & Carburization* & $32 \mathrm{Cr} 3 \mathrm{MoVA}$ & Nitridation* & 100 & 200 \\
\hline 9 & $18 \mathrm{CrNi} 4 \mathrm{~A}$ & Carburization & $18 \mathrm{CrNi} 4 \mathrm{~A}$ & Carburization & 50 & 200 \\
\hline 10 & $18 \mathrm{CrNi} 4 \mathrm{~A}$ & Carburization & $18 \mathrm{CrNi} 4 \mathrm{~A}$ & Carburization & 120 & 200 \\
\hline 11 & $18 \mathrm{CrNi} 4 \mathrm{~A}$ & Carburization & $18 \mathrm{CrNi} 4 \mathrm{~A}$ & Carburization & 150 & 200 \\
\hline 12 & $18 \mathrm{CrNi} 4 \mathrm{~A}$ & Carburization & $18 \mathrm{CrNi} 4 \mathrm{~A}$ & Carburization & 100 & 150 \\
\hline 13 & $18 \mathrm{CrNi} 4 \mathrm{~A}$ & Carburization & $18 \mathrm{CrNi} 4 \mathrm{~A}$ & Carburization & 100 & 260 \\
\hline 14 & $18 \mathrm{CrNi} 4 \mathrm{~A}$ & Carburization & $18 \mathrm{CrNi} 4 \mathrm{~A}$ & Carburization & 100 & 360 \\
\hline
\end{tabular}

Note: the superscript "** denotes that the material is silvered on the carburization or nitridation layers.

TABLE 4: Friction coefficient.

\begin{tabular}{lccccccc}
\hline Groups & 1 & 2 & 3 & 4 & 5 & 6 & 7 \\
Friction coefficient & 0.1208 & 0.1068 & 0.1494 & 0.1269 & 0.1196 & 0.1148 \\
Groups & 8 & 9 & 10 & 11 & 12 & 0.0661 \\
Friction coefficient & 0.0717 & 0.1307 & 0.1109 & 0.1059 & 0.1167 & 13 \\
\hline
\end{tabular}

TABle 5: Wear coefficient.

\begin{tabular}{lcccc}
\hline Groups & $\begin{array}{c}\text { Wear } \\
\text { weight }(\mathrm{g})\end{array}$ & $\begin{array}{c}\text { Wear volume } \\
\left(\mathrm{cm}^{3}\right)\end{array}$ & $\begin{array}{c}\text { Slide distance } \\
(\mathrm{mm})\end{array}$ & $\begin{array}{c}\text { Wear } \\
\text { coefficient }\end{array}$ \\
\hline 1 & 0.0002 & 0.0256 & 1707657.6 & $0.0884 \times 10^{-8}$ \\
2 & 0.0004 & 0.0513 & 1818436.8 & $1.6603 \times 10^{-8}$ \\
3 & 0.0044 & 0.5641 & 1818436.8 & $18.2639 \times 10^{-8}$ \\
4 & 0.0059 & 0.7564 & 1838784.0 & $24.2191 \times 10^{-8}$ \\
5 & 0.0179 & 2.2948 & 1773974.4 & $76.1632 \times 10^{-8}$ \\
6 & 0.0045 & 0.5769 & 1887768.0 & $17.9930 \times 10^{-8}$ \\
7 & 0.0010 & 0.1282 & 1778496.0 & $4.2441 \times 10^{-8}$ \\
8 & 0.0050 & 0.6410 & 1846320.0 & $20.4410 \times 10^{-8}$ \\
9 & 0.0001 & 0.0128 & 1782264.0 & $0.4235 \times 10^{-8}$ \\
10 & 0.0011 & 0.1410 & 1811654.4 & $4.5831 \times 10^{-8}$ \\
11 & 0.0013 & 0.1667 & 1751366.4 & $5.6028 \times 10^{-8}$ \\
12 & 0.0046 & 0.5897 & 1844812.8 & $18.8211 \times 10^{-8}$ \\
13 & 0.0003 & 0.0385 & 1746091.2 & $1.2969 \times 10^{-8}$ \\
14 & 0.0026 & 0.3333 & 1782264.0 & $11.0114 \times 10^{-8}$ \\
\hline
\end{tabular}

2.3.2. Wear Coefficient and Depth. Figure 3 depicts the variations of wear coefficient with friction time under different conditions. From Figures 3(a)-3(d), it can be concluded that the wear coefficient increases with the increasing friction time. The material of pin specimens is carburized $18 \mathrm{CrNi} 4 \mathrm{~A}$, and the plate made of nontreated $32 \mathrm{Cr} 3 \mathrm{MoVA}$ (number 3 couple) possesses higher wear coefficient about $7.62 \times 10^{-7}$ $\mathrm{kPa}^{-1}$ after $120 \mathrm{~min}$ testing. The plate made of nontreated $18 \mathrm{CrNi} 4 \mathrm{~A}$ (number 1 couple) has relatively low wear coefficient around $1.66 \times 10^{-8} \mathrm{kPa}^{-1}$ (Figure $3(\mathrm{a})$ ). It relates to the hardness of the materials.

From Figure 3(b), the plate treated by carburization or nitridation has lower wear coefficient compared to the nontreated cases shown in Figure 3(a). After a silvering layer formed on the carburization or nitridation layers, the wear coefficient is increased (number 6 and 8 couples). The couple made of carburized 18CrNi4A (number 5 couple) possesses lower wear coefficient of $8.84 \times 10^{-9} \mathrm{KPa}^{-1}$ after $120 \mathrm{~min}$ testing. These suggest that the pins and plate are fabricated by the same material $18 \mathrm{CrNi} 4 \mathrm{~A}$ with carburization layer and without silvering.

Meanwhile, the wear coefficient increases with the increasing load, which exhibits an increasing tendency followed by a decrease as the rotation speed increases (Figures 3(c) and 3(d)).

In order to further understand the wear property, the depth of worn trace on the plate specimen was measured. Figure 4 shows the variations of wear depth. It can be seen that the wear depth increases with the increasing friction time. From Figure 4(a), when the pins are made of carburized $18 \mathrm{CrNi} 4 \mathrm{~A}$, the wear depth of plate specimen made of nontreated $32 \mathrm{Cr} 3 \mathrm{MoVA}$ is higher than that of nontreated $18 \mathrm{CrNi} 4 \mathrm{~A}$. In the case of the nontreated pins, the wear depth of plate is opposite to the former. Among these couples, the 
TABLe 6: Wear depth.

\begin{tabular}{|c|c|c|c|c|c|c|c|}
\hline Groups & 1 & 2 & 3 & 4 & 5 & 6 & 7 \\
\hline Wear area $\left(\mathrm{mm}^{2}\right)$ & 273.6271 & 273.8906 & 134.1097 & 275.8176 & 224.7034 & 200.5754 & 200.0808 \\
\hline Wear depth (mm) & $9.37 \times 10^{-5}$ & $18.72 \times 10^{-5}$ & $420.63 \times 10^{-5}$ & $274.24 \times 10^{-5}$ & $1021.28 \times 10^{-5}$ & $287.63 \times 10^{-5}$ & $64.08 \times 10^{-5}$ \\
\hline Groups & 8 & 9 & 10 & 11 & 12 & 13 & 14 \\
\hline Wear area $\left(\mathrm{mm}^{2}\right)$ & 261.5620 & 271.0527 & 223.4374 & 216.0019 & 221.3775 & 278.6471 & 256.2005 \\
\hline Wear depth (mm) & $245.08 \times 10^{-5}$ & $4.73 \times 10^{-5}$ & $63.12 \times 10^{-5}$ & $77.16 \times 10^{-5}$ & $266.39 \times 10^{-5}$ & $13.80 \times 10^{-5}$ & $130.11 \times 10^{-5}$ \\
\hline
\end{tabular}

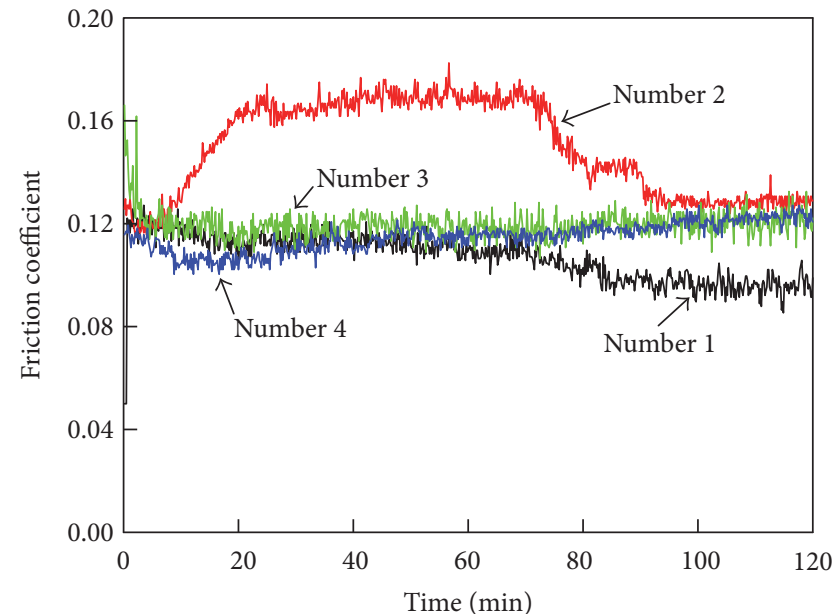

(a)

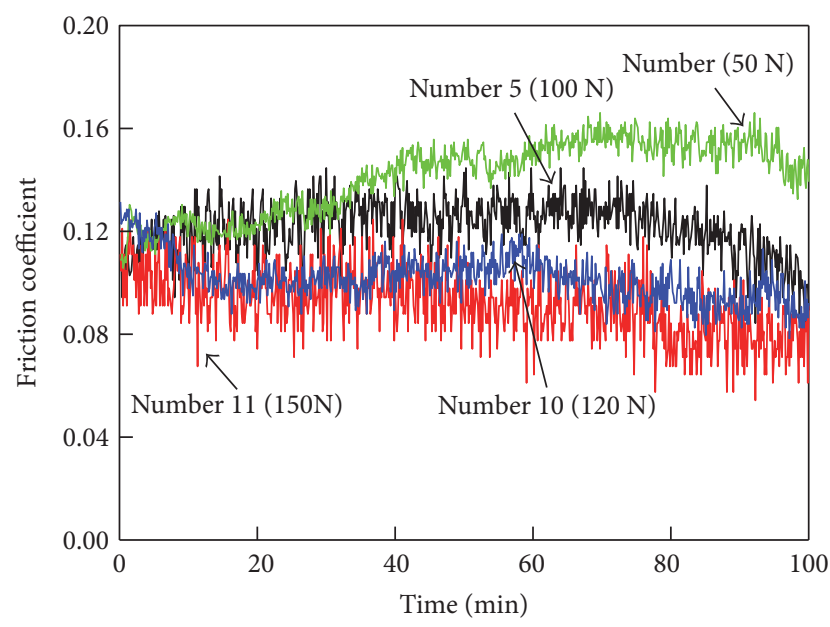

(c)

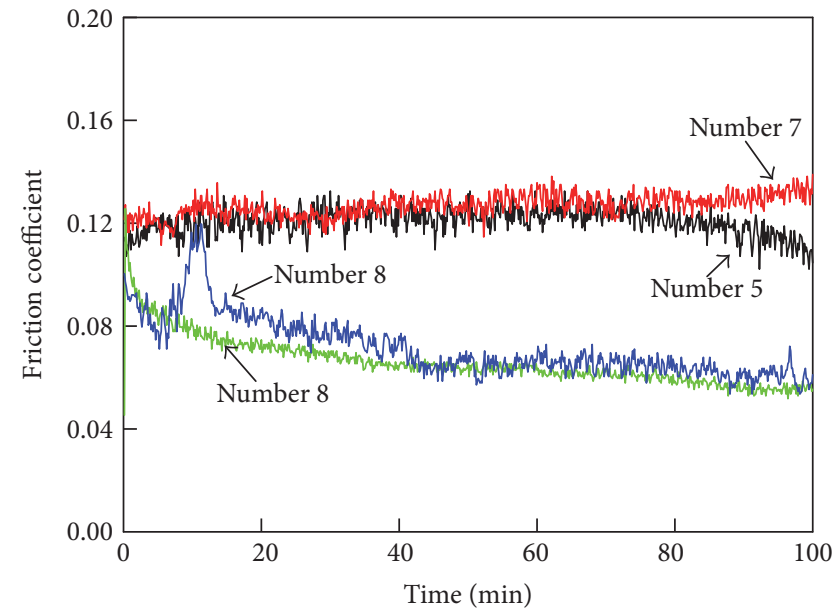

(b)

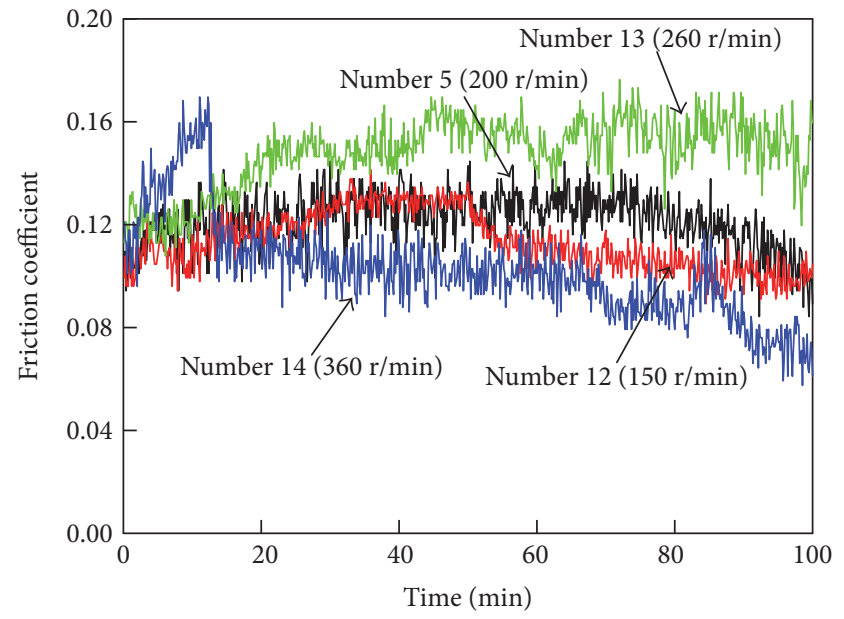

(d)

Figure 2: Variations of friction coefficient with time under different materials (a), surface treatments (b), loads (c), and rotation speeds (d).

plate of couple number 3 has higher wear depth, and its maximum value is $10.2 \mu \mathrm{m}$ after $120 \mathrm{~min}$ testing. The reason for this phenomenon is that the hardness of the pins made of carburized $18 \mathrm{CrNi} 4 \mathrm{~A}$ is higher than the others. The plate of couple number 1 possesses relatively low wear depth. These suggest that alloy steel $18 \mathrm{CrNi} 4 \mathrm{~A}$ has better wear resistance than $32 \mathrm{Cr} 3 \mathrm{MoVA}$ under the nontreatment state.

From Figure 4(b), the wear depth of plate is decreased via the carburization or nitridation treatments under the pins made of carburized $18 \mathrm{CrNi} 4 \mathrm{~A}$. However, the wear depth increases after silvering layer formed on the carburization or nitridation layers. The treated plate has higher wear resistance than the nontreated one. Among these friction couples, couple number 5 made of carburized $18 \mathrm{CrNi} 4 \mathrm{~A}$ has relatively low wear depth of about $0.09 \mu \mathrm{m}$ after $120 \mathrm{~min}$ testing. Also, Figure 4(c) shows that the wear depth increases with the increasing load. As the rotation speed increases, the wear depth exhibits a decreasing trend followed by an increase as 


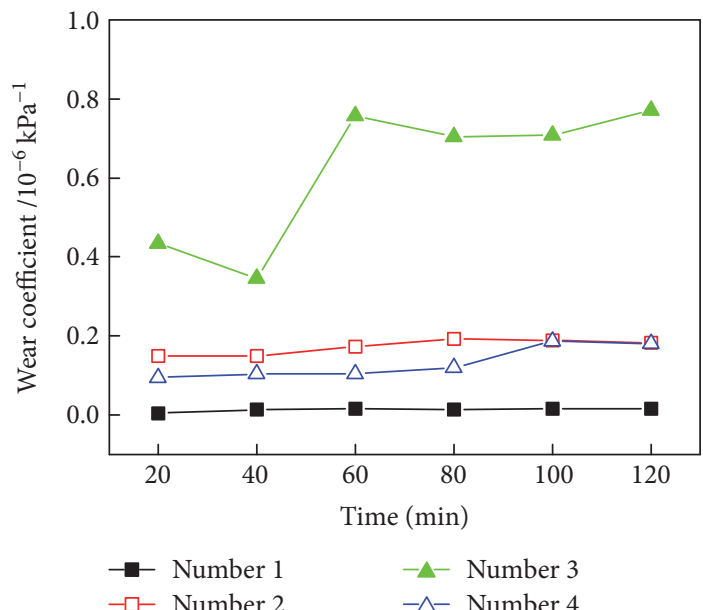

(a)

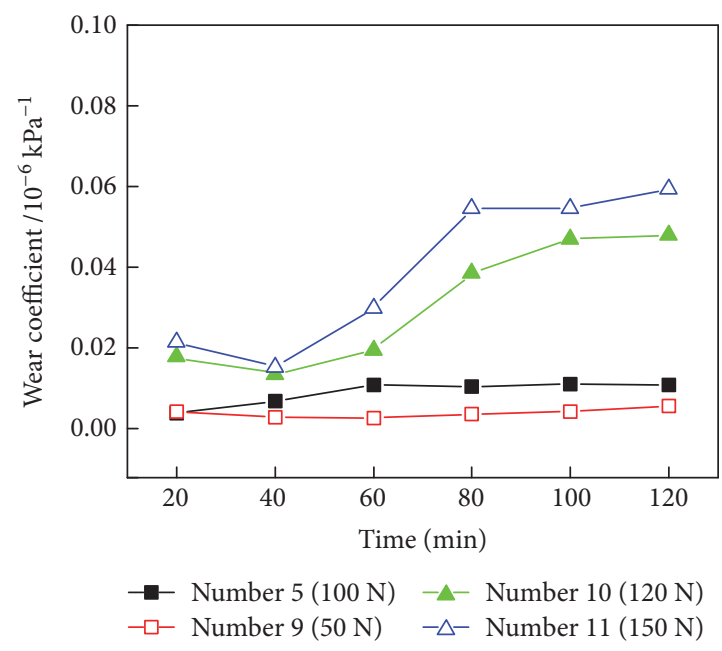

(c)

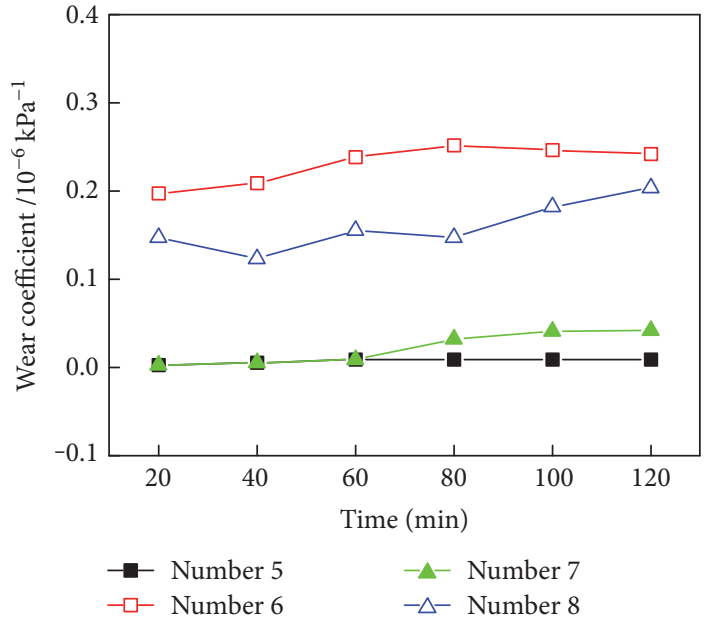

(b)

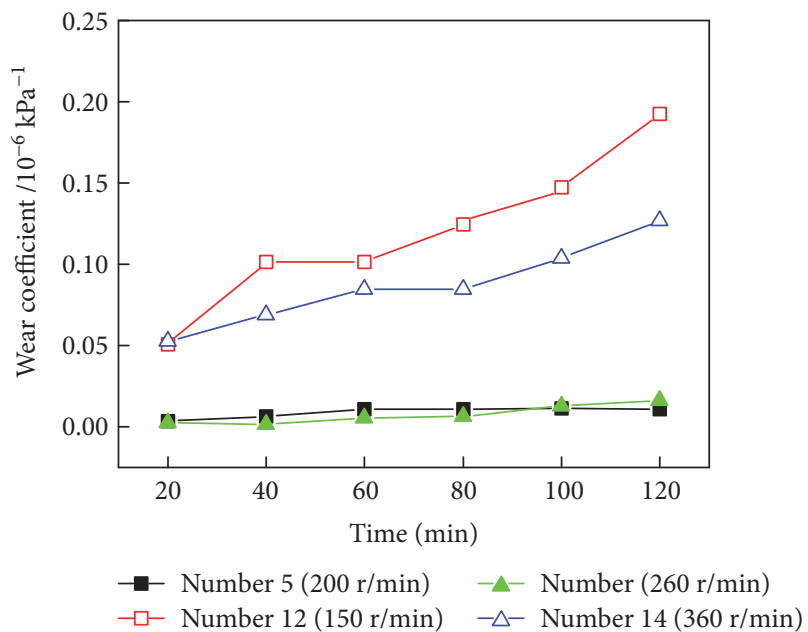

(d)

Figure 3: Variations of wear coefficient with time under different materials (a), surface treatments (b), loads (c), and rotation speeds (d).

shown in Figure 4(d). After 120 min testing, the wear depth reaches the minimum of about $0.09 \mu \mathrm{m}$ at $200 \mathrm{r} / \mathrm{min}$ and the maximum of about $2.66 \mu \mathrm{m}$ at $150 \mathrm{r} / \mathrm{min}$.

In general, from Figures $2-4$, it can be gotten that there are some inconsistencies between the results of friction coefficient and the results of wear depth. It is caused by the different mechanical properties and hardness of pins and plates. Meanwhile, the pins have higher wear resistance than the plates because of the differences in the geometry. Thus, the contact stress and slide distance can be calculated from above parameters.

\section{Prediction of Wear of Specimen}

Prediction of the wear is very significant for designing aeroengine spline couplings with high performance. In order to predict the wear in spline couplings accurately, a good method is necessary. Here, a method was proposed to predict the wear of the material specimens with an Archard's equation as well as finite element method. Based on it, the wear of the floating spline couplings was predicted.

After the solid model established using $\mathrm{PRO} / \mathrm{E}$ was imported into ANSYS, the global coordinate system should be converted into column coordinate system. The physical and mechanical properties used for building the finite element models were shown in Table 7 , and then the finite element models of the pin-on-plate friction couple were established as shown in Figure 5. And, at this time, the nodal coordinate systems of each node should also be converted into column coordinate system. The target and contact surfaces correspond to the internal and external splines. The selected contact stiffness factor FKN is 1.0 [21], the contact pairs were established. According to the moving rules of pin-on-plate friction couple in the test, the plate surface was constrained completely, and the freedom of three pins was constrained completely too except for the freedom degrees of circumferential rotation degrees. Next, the loads were applied according to the experiment conditions listed in Table 3. 


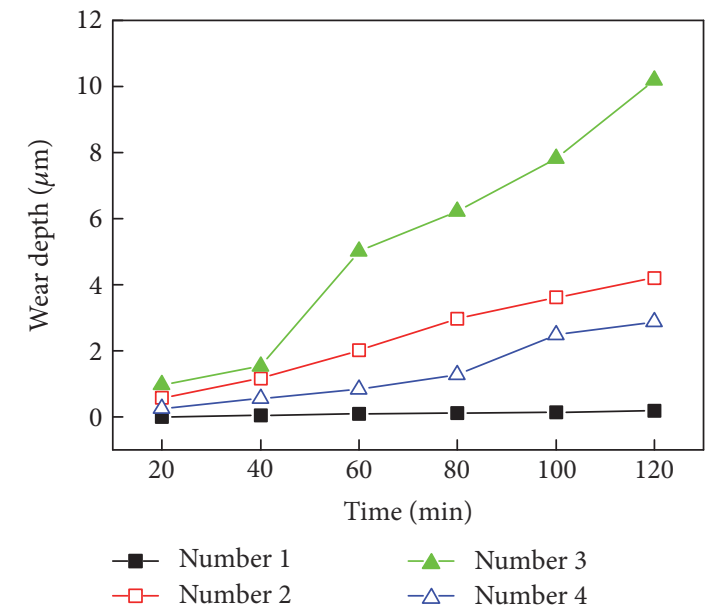

(a)

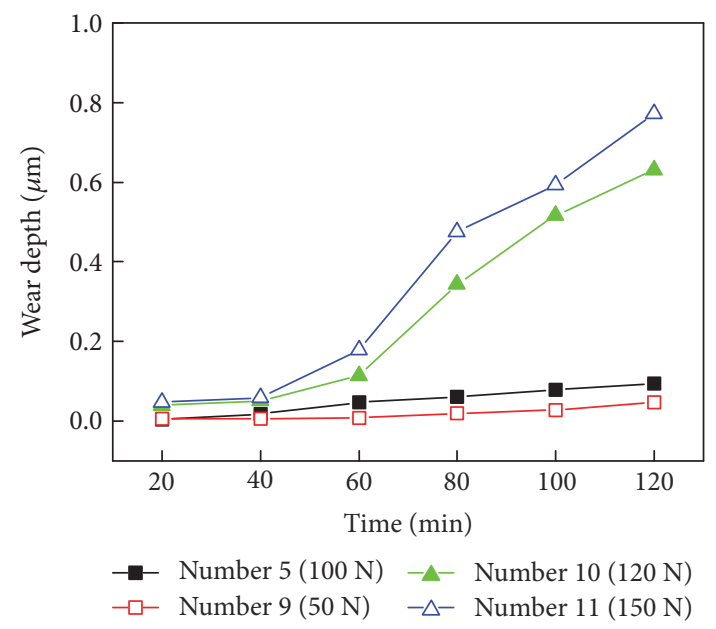

(c)

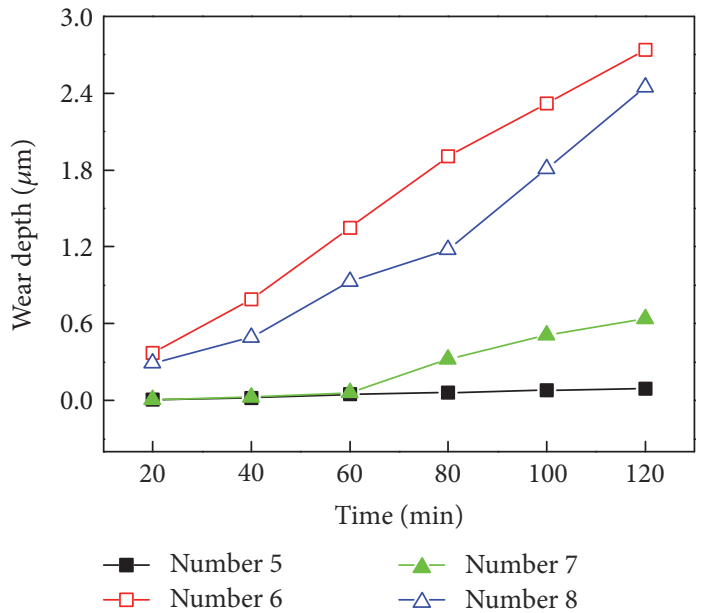

(b)

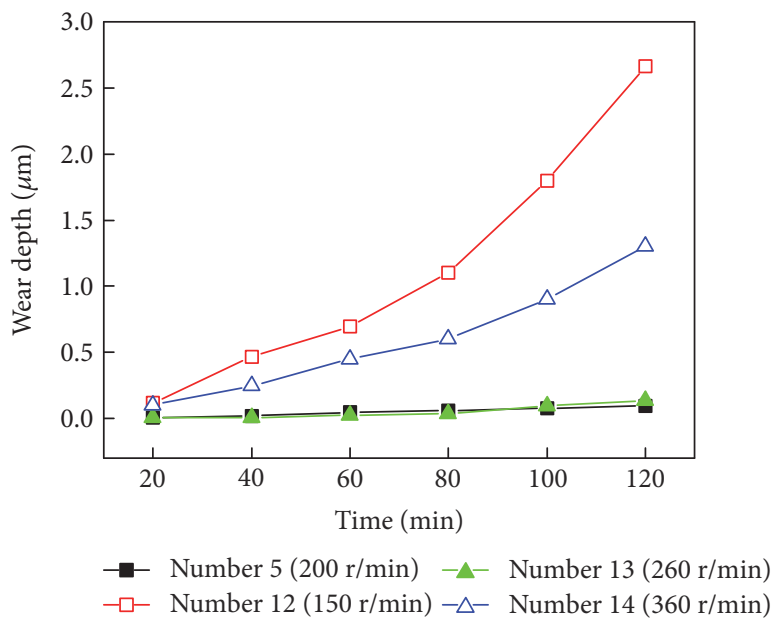

(d)

Figure 4: Variations of wear depth with time under different materials (a), surface treatments (b), loads (c), and rotation speeds (d).

TABLE 7: Physical and mechanical properties for building the finite element models.

\begin{tabular}{lcccc}
\hline $\begin{array}{l}\text { Unit } \\
\text { type }\end{array}$ & $\begin{array}{c}\text { Modulus of } \\
\text { elasticity }\end{array}$ & Density & $\begin{array}{c}\text { Friction } \\
\text { coefficient }\end{array}$ & $\begin{array}{c}\text { Poisson } \\
\text { ratio }\end{array}$ \\
\hline Solid185 & $210 \mathrm{GPa}$ & $7.800 \mathrm{~g} / \mathrm{cm}^{3}$ & 0.12 & 0.28 \\
\hline
\end{tabular}

The wear depth of the plate specimen is predicted using Archard's equation (7) [22]. Basing on this equation, the wear depth of one minor cycle can be expressed by (8).

$$
\begin{aligned}
h(x) & =2 k \cdot s(x) \cdot p(x), \\
\Delta h_{j}(x) & =2 k \cdot s(x) \cdot p(x),
\end{aligned}
$$

where $h(x)$ is the wear depth in one cycle of $x$; $k$ is the wear coefficient obtained from friction testing; $s(x)$ is the slide distance of $x ; p(x)$ is the contact stress of $x ; j(j=1,2,3, \ldots, t)$ is the number of load cycle; $s(x)=l \times z$.

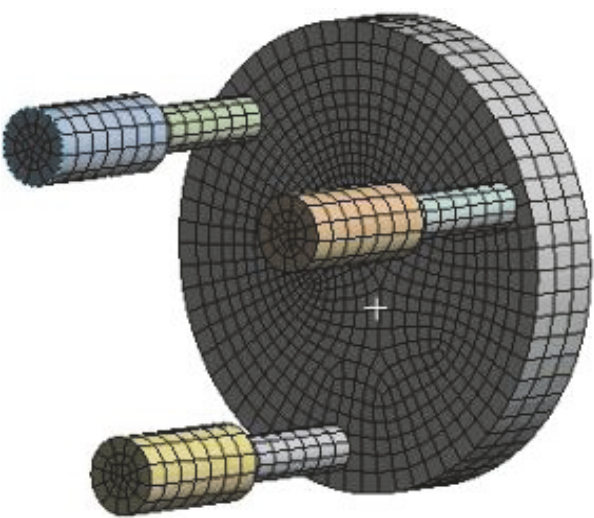

FIGURE 5: Finite element model of pin-on-plate friction couple.

The model of pin-on-plate friction couple is modified according to $\Delta h_{j}(x)$ in $\mathrm{PRO} / \mathrm{E}$. Therefore, the finite element model and contact couple can be renewed. The contact stress and sliding distance are calculated once again as 


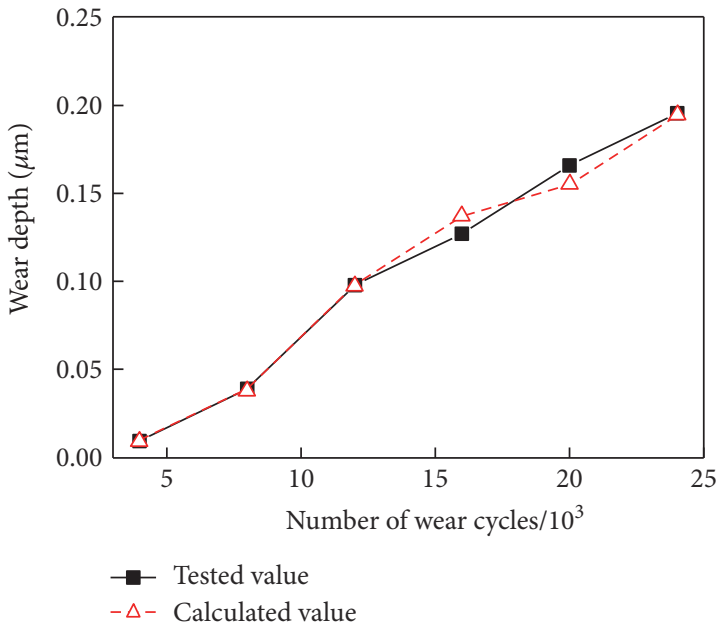

(a)

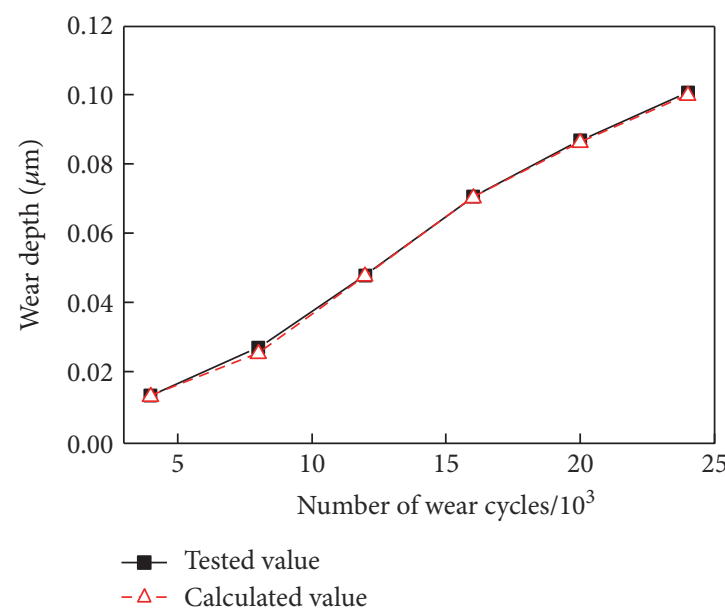

(c)

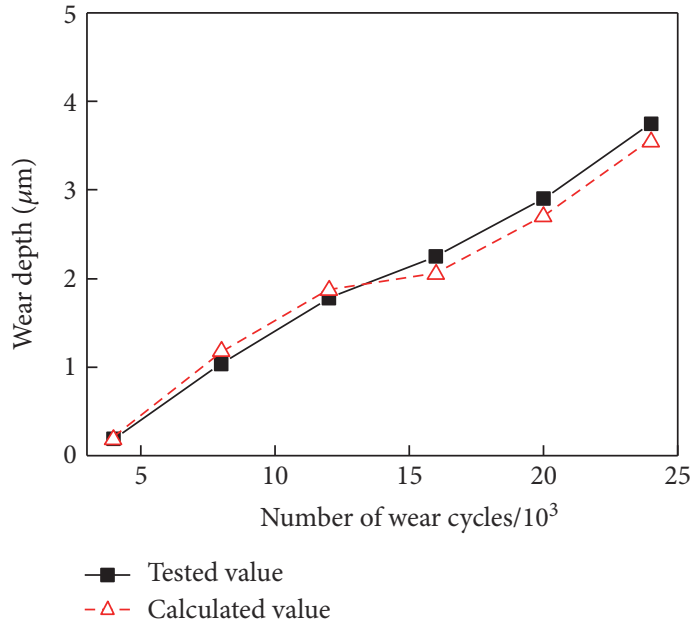

(b)

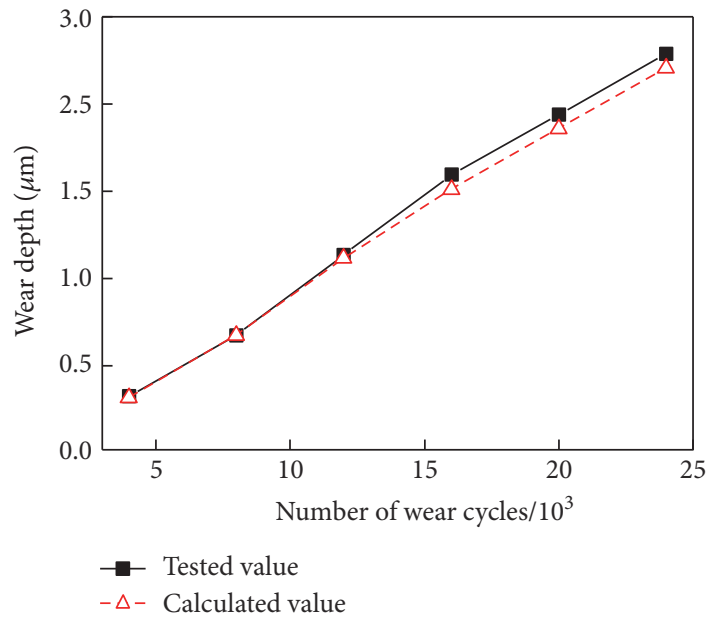

(d)

FIGURE 6: Wear depth of the friction couple number 1 (a), number 2 (b), number 5 (c), and number 7 (d).

well as the wear depth of one minor cycle in the modified model. After the cycles of $N_{t}-1$ iteration, the wear depth can be expressed by

$$
h=\sum_{j=1}^{N_{t}} \Delta h_{j} .
$$

Actually, the wear depth of one minor cycle can be neglected since the value is too small to modify the model. It is necessary to select $\Delta N$ as the increment of wear cycle [18]. Therefore, the wear depth of one wear cycle is as follows:

$$
\Delta h_{\Delta N}=2 k \cdot \Delta N \cdot s(x) \cdot p(x) .
$$

From (10), the total wear depth of friction couple can be described using

$$
h=\sum_{i=1}^{N_{t} / \Delta N} \Delta h_{i}
$$

where $i$ is the number of wear cycle increment, $i=1,2,3$, $\ldots, N_{t} / \Delta N, \Delta N$ is 4000 under the $N_{t}=24000$, and the wear coefficient $k$ is the average value obtained in Figure 2.

Figure 6 depicts the calculated and tested wear depths. It can be seen that the wear depth calculated via finite element models is nearly the same to the tested value. From Figure 6, the wear depth of the friction of couple numbers 1 and 5 is less than that of couple number 2 and couple number 7 . The wear depth of the former two couples is approximate to zero when the number of wear cycle is less than 6000 . As the number of wear cycle increases, the wear depth presents an increasing trend. When the number of wear cycle is increased to 24000, the wear depth of the former two couples (numbers 1 and 5) is less than $0.19 \mu \mathrm{m}$. Especially for couple number 5 , its wear depth reaches the minimum of about $0.09 \mu \mathrm{m}$. It also can be obtained from Figure 6 that the results of calculated value are consistent with the results of tested value. This indicates that the method of calculating wear proposed here is feasible and can provide an accurate basis for the predicting wear of floating spline coupling. 
TABLE 8: Geometric parameters of floating involute spline.

\begin{tabular}{lcccc}
\hline $\begin{array}{l}\text { Number } \\
\text { of teeth }(z)\end{array}$ & $\begin{array}{c}\text { Press } \\
\text { anger }(a)\end{array}$ & $\begin{array}{c}\text { Contact } \\
\text { length }(L)\end{array}$ & $\begin{array}{c}\text { Thickness of } \\
\text { tooth top }(B)\end{array}$ & $\begin{array}{c}\text { Pitch diameter } \\
(D)\end{array}$ \\
\hline 22 & $30^{\circ}$ & $27.5(\mathrm{~mm})$ & $2.4(\mathrm{~mm})$ & $55(\mathrm{~mm})$ \\
\hline
\end{tabular}
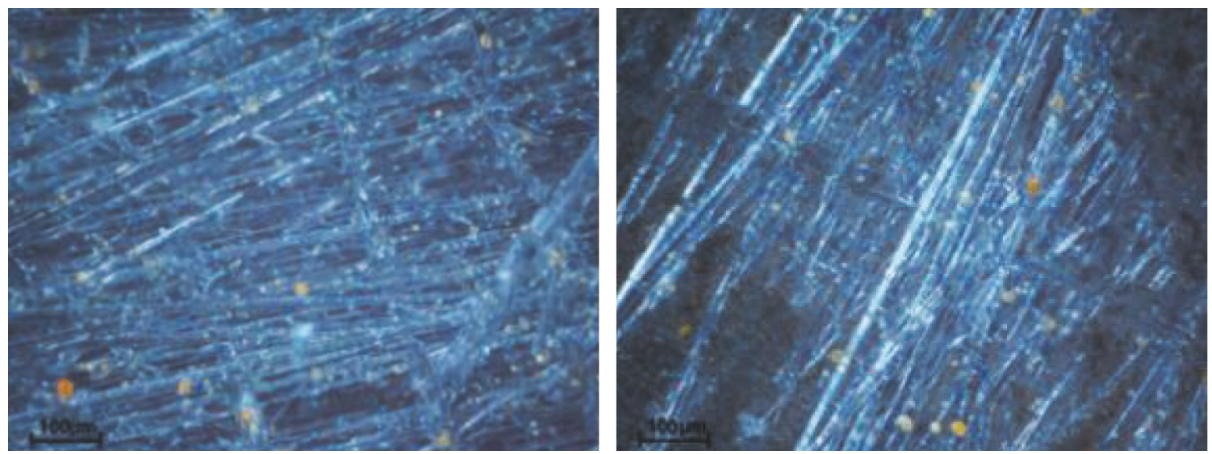

FIGURE 7: Surface topography by industrial microscopes of worn material specimen.
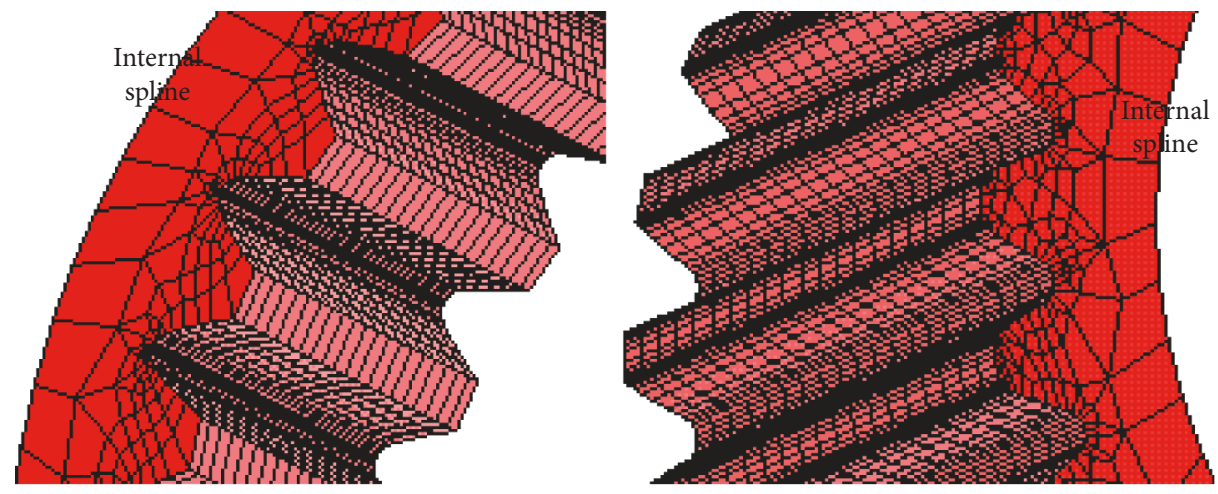

Figure 8: Finite element model of spline coupling.

\section{Prediction of Wear of Floating Involute Spline}

4.1. Prediction of Contact Stress. Table 8 shows the geometric parameters of the wear of a floating involute spline. The axial sliding distance of this floating spline coupling is $2 \mathrm{~mm}$. The surface morphology of worn spline teeth was observed by an industrial microscope to analyze the wear form. From the morphology of worn spline teeth measured by industrial microscopes (Figure 7), many furrows and wear debris can be found on the worn surface because of the long range reciprocating sliding $(>100 \mu \mathrm{m})$. It is a representative characteristic of abrasive wear (mechanical wear), and it implies that the damage in floating spline coupling is caused mainly by abrasive wear. In Section 2, the specimens were doing the mechanical sliding, and its mechanism is mechanical wear and similar to that of the floating spline coupling because they all suffer the long range reciprocating sliding $(>100 \mu \mathrm{m})$. Moreover, the method proposed in Section 3 for calculating the wear of specimens is consistent with testing results of Section 2. Therefore, this method can be used to predict the wear depth of floating involute spline.

The process of establishing the finite element model (Figure 8) and contact pair of floating involute spline coupling is similar as pin-on-plate friction couple. The differences are the ways to constrain and load.

According to the moving mode of spline coupling, the external cylindrical surface of internal spline was constrained completely. The degree of freedom of external spline coupling was constrained except for the Y direction. Meanwhile, the torque is expressed as follows:

$$
T(t)=T_{m}\left(1+\varepsilon_{T} \cdot \cos \left(\omega_{T} \cdot t\right)\right)
$$

where $T_{m}$ is the average torque; $\varepsilon_{T}$ is the fluctuation coefficient of torque, $\varepsilon_{T}=0.1 ; \omega_{T}$ is the angular velocity of system; $n$ is the rotation speed of the system. The torque of one minor cycle $(0-2 \pi)$ is separated into 5 steps $T_{i}(i=1,2,3,4$, and 5$)$. According to the equation $\omega_{T}=2 n \pi / 60$, the one minor 
cycle is $\tau=60 / n$. The load applied to the model is calculated using (7).

$$
F_{i}=\frac{T_{i}}{(r \cdot N)},
$$

where $D$ is the pitch circle diameter of external spline, $r$ is the hole radius of the external spline $(r=0.8 D / 2)$, and $N$ is the node number in the hole of the external spline.

The force calculated using (7) is applied on the internal cylindrical surface of the external spline coupling along the $y$ direction, and displace of $s$ (given by designer) along the $x$ direction is applied too. Because the distance $s$ caused by axial movement of floating spline coupling is much bigger than the distance caused by fretting movement, the distance caused by fretting movement is neglected here. And then, the model is solved, and the contact stress is achieved.

4.2. The Wear of Floating Spline Coupling. For simplifying the wear of spline coupling, the floating distance is set as $2 \mathrm{~mm}$. The elastic distortion and damage caused by fretting wear are all neglected. The wear of floating spline coupling in one minor cycle is defined as follows [10]:

$$
\Delta h_{j}(x)=2 k \sum_{i=1}^{5} s \cdot p(x)_{i} .
$$

Here, $s=2 \mathrm{~mm}$. When the number of load cycle is $N_{t}$, the wear of the floating spline coupling is defined as follows:

$$
h=\sum_{j=1}^{N_{t}} \Delta h_{j} .
$$

Then, in one wear cycle incremental $(\Delta N)$ [17], the wear of floating spline coupling is as follows [10]:

$$
\Delta h_{\Delta N_{j}}(x)=2 k \Delta N \sum_{i=1}^{5} s \cdot p(x)_{i} .
$$

The total wear depth of floating spline coupling is as follows:

$$
h=\sum_{l=1}^{N_{t} / \Delta N} \Delta h_{l}
$$

In the model, $N_{t}$ and $\Delta N$ are 120000 and 60000, respectively. The wear coefficient $k$ is the average value of each group tested in Section 2.2. The calculation of the wear of the spline coupling geometric parameters is shown in Table 3 , and the materials and heat treatment are listed in Section 2.1. When the input power $P$ is $1015 \mathrm{~kW}$, the rotation speed $n$ is $5915 \mathrm{rpm}$. When the axial distances of floating are $2.0 \mathrm{~mm}, 2.5 \mathrm{~mm}$, and $3.0 \mathrm{~mm}$, the calculated results of wear are shown in Figure 9.

\section{Conclusions}

This work investigates the effect of materials, loads, rotation speed, and surface treatment on friction coefficient, wear coefficient, and wear depth, and the wear prediction for

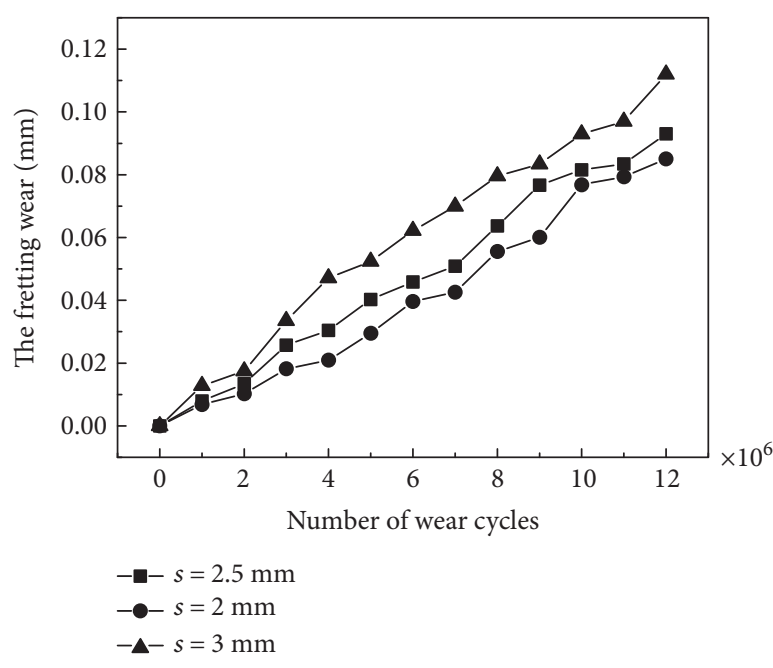

Figure 9: Wear depth results of the spline coupling.

floating spline coupling is proposed. From the work, it can be gotten that the friction coefficient of the specimen can be decreased by carburizing and silvering. The material couple has an impact on the friction process. The friction coefficient decreases when the load is increasing, whereas it increases when the rotation is increasing. Carburization or nitridation can decrease wear coefficient, whereas silvering on the carburization or nitridation layers can increase wear coefficient. And, carburization or nitridation treatments can decrease wear depth, whereas silvering on the carburization or nitridation layers can increase wear depth. It also can be gotten that there are some inconsistencies between the results of friction coefficient and results of wear depth. It is mainly caused by the different mechanical properties and hardness of pins and plates. Meanwhile, the pins have higher wear resistance than the plates because of the differences in the geometry. In other words, $18 \mathrm{CrNi} 4 \mathrm{~A}$ with carburization and $32 \mathrm{Cr} 3 \mathrm{MoVA}$ with nitridation should be the material of the spline coupling in aero-engine.

At the same time, the method proposed here to calculate the wear of floating involute spline was feasible. From the result, it can be concluded that the wear depth increases with the axial floating distance increasing. So, the distance of axial floating must be designed as small as possible. It provides a basis for predicting the fatigue life of the spline coupling. It also gives an accurate value based on the design of spline coupling.

\section{Conflicts of Interest}

The authors declare that there is no conflict of interests regarding the publication of this paper.

\section{Acknowledgments}

The authors gratefully acknowledge the financial support of the National Natural Science Foundation of China (Grant no. 51175422). 


\section{References}

[1] S. Medina and A. V. Olver, "An analysis of misaligned spline coupling," Journal of Engineering Tribology, vol. 216, pp. 269-279, 2002.

[2] C. H. Wink and M. Nakandakar, "Influence of gear loads on spline coupling," Power Transmission Engineering, vol. 3, pp. 41-49, 2014.

[3] G. N. D. S. Sudhakar and A. S. Sekhar, "Coupling misalignment in rotating machines: modelling, effects and monitoring," Noise \& Vibration worldwide, vol. 8, pp. 17-39, 2009.

[4] D. C. H. Yang and S. H. Tong, "On the profile design of transmission splines and keys," Mechanism and Machine Theory, vol. 42, pp. 82-87, 2007.

[5] W. S. Sum, S. B. Leen, E. J. Williams, R. Sabesan, and I. R. McColl, "Efficient finite element modelling for complex shaft couplings under non-symmetric loading," The Journal of Strain Analysis for Engineering Design, vol. 40, pp. 655-673, 2005.

[6] S. Fouvry, "Shakedown analysis and wear response under gross slip condition," Wear, vol. 251, pp. 1320-1331, 2001.

[7] T. R. HYDE, S. B. LEEN, and I. R. MCCOLL, "A simplified fretting test methodology for complex shaft couplings," Fatigue \& Fracture of Engineering Materials \& Structures, vol. 28, pp. 1047-1067, 2005.

[8] J. J. Madge, S. B. Leen, I. R. McColl, and P. H. Shipway, "Contact-evolution based prediction of fretting fatigue life: effect of slip amplitude," Wear, vol. 262, pp. 1159-1170, 2007.

[9] J. J. Madge, S. B. Leen, and P. H. Shipway, "The critical role of wear in the analysis of fretting fatigue," Wear, vol. 263, pp. 542-551, 2007.

[10] J. Ding, I. R. McColl, and S. B. Len, “The application of fretting wear modelling to a spline coupling," Wear, vol. 262, pp. 1205-1216, 2007.

[11] D. Houghton, P. M. Wavish, E. J. Williams, and S. B. Leen, "Multiaxial fretting fatigue testing and prediction for splined couplings," International Journal of Fatigue, vol. 31, pp. 1805-1815, 2009.

[12] C. H. H. Ratsimba, I. R. McColl, E. J. Williams, S. B. Leen, and H. P. Soh, "Measurement, analysis and prediction of wear damage in a representative aeroengine spline coupling," Wear, vol. 257, pp. 1193-1206, 2004.

[13] I. R. McColl, J. Ding, and S. B. Leen, "Finite element simulation and experimental validation of wear," Wear, vol. 256, pp. 1114-1127, 2004.

[14] V. Cuffaro, F. Cura, and A. Mura, "Test rig for spline coupling working in misaligned conditions," Journal of Tribology, vol. 136, pp. 1-7, 2014.

[15] V. Cuffaro, F. Cura, and A. Mura, "Damage identification on spline coupling teeth by means of roughness parameters," Theoretical and Applied Fracture Mechanics, vol. 82, pp. 9-16, 2016.

[16] Y. Guo, S. Lambert, R. Wallen, R. Errichello, and J. Keller, "Theoretical and experimental study on gear-coupling contact and loads considering misalignment, torque, and friction influences," Mechanism and Machine Theory, vol. 98, pp. 242-262, 2016.

[17] S. B. Leen, T. R. Hyde, E. J. Williams et al., "Development of a representative test specimen for frictional contact in spline joint couplings," The Journal of Strain Analysis for Engineering Design, vol. 35, pp. 521-544, 2000.
[18] S. B. Leen, I. J. Richardson, I. R. McColl, E. J. Williams, and T. R. Hyde, "Macroscopic fretting variables in a splined coupling under combined torque and axial load," The Journal of Strain Analysis for Engineering Design, vol. 36, pp. 481-497, 2001.

[19] S. B. Leen, T. H. Hyde, C. H. H. Ratsimba, E. J. Williams, and I. R. McColl, "An investigation of the fatigue and fretting," The Journal of Strain Analysis for Engineering Design, vol. 37, pp. 565-583, 2003.

[20] Z. G. Hu, R. P. Zhu, G. H. Jin, and D. Ni, "Analysis of fretting frictional contact parameters of aviation involute spline coupling," Journal of Central South University (Science and Technology), vol. 44, pp. 1822-1828, 2013.

[21] J. Hong, D. Talbot, and A. Kahraman, "Load distribution analysis of clearance-fit spline joints using finite elements," Mechanism and Machine Theory, vol. 74, pp. 42-57, 2014.

[22] A. Barrot, M. Paredes, and M. Sartor, "Extended equations of load distribution in the axial direction in a spline coupling," Engineering Failure Analysis, vol. 16, pp. 200-211, 2009. 


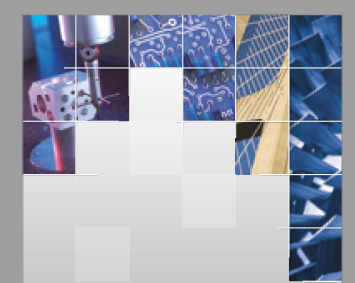

\section{Enfincering}
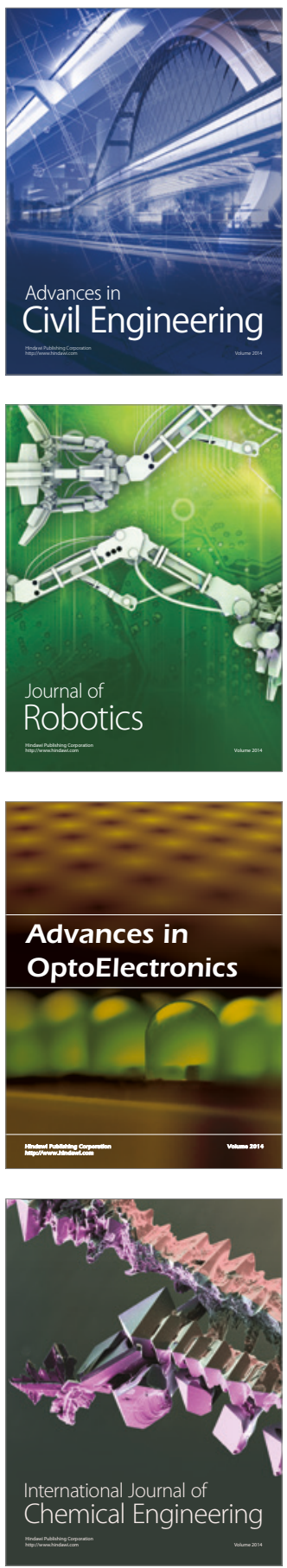

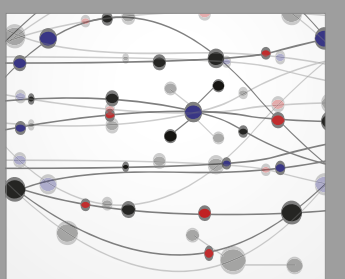

The Scientific World Journal

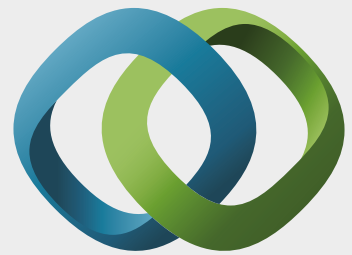

\section{Hindawi}

Submit your manuscripts at

https://www.hindawi.com
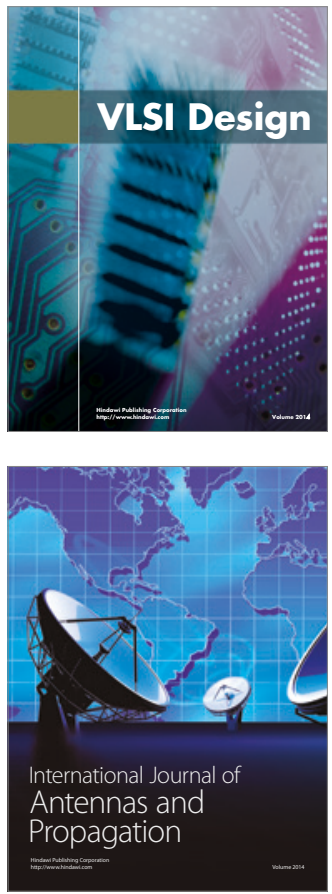

\section{Rotating}

Machinery
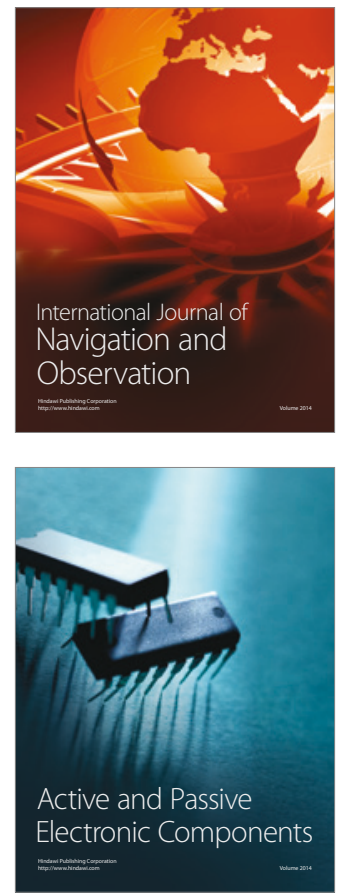
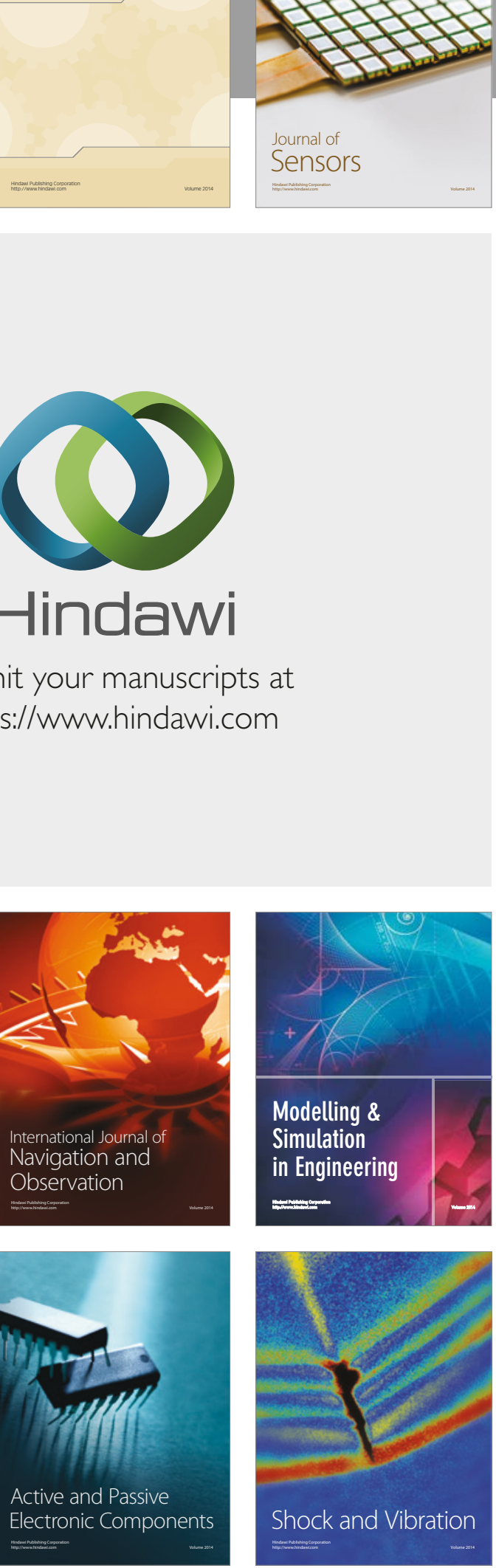
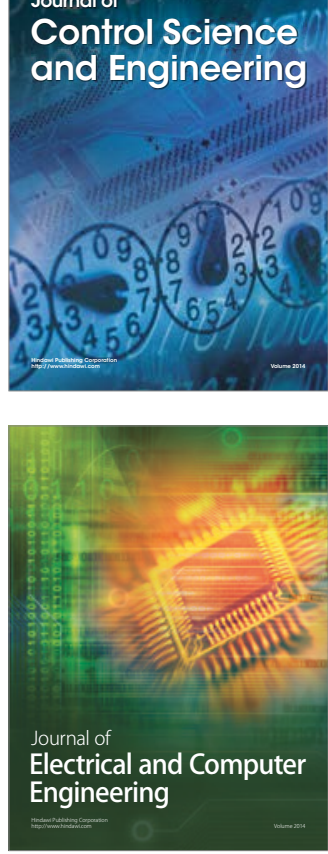

Distributed

Journal of

Control Science

and Engineering
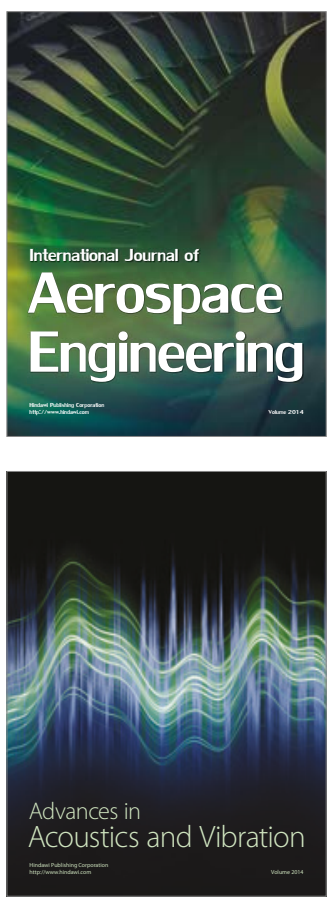

Sensor Networks 